\title{
EYE TRACKING: A NEW EVOLUTION IN TECHNOLOGY
}

\author{
Nikita Marwah \\ Student (MCA) \\ Jagan Institute of Management Studies \\ Sector-5, Rohini, Delhi-110085, India
}

\author{
Latika Kharb \\ Professor \\ Jagan Institute of Management Studies \\ Sector-5, Rohini, Delhi-110085, India
}

\begin{abstract}
Technology has always been seen on a changing track. Every year, the ongoing technologies go through some finer advancement. These advancements not only make a nation technically powerful but also create new knowledge among the young aspiring minds. And being in 21st century is not an easy deal. A good number of primary firms are there which are strengthening the understandings of new automation concepts among the community and enhancing the civilian technological evolutions.

And what when these evolutions got invoked with smooth reading of human minds. Yes, it sounds great. Eye tracking is one of these evolutions which also made me astonished, for once. One can easily imagine the uniqueness of this concept and at the same time, the interpretation wouldn't be facile.
\end{abstract}

\section{CONCEPT BEHIND EYE-TRACKING}

Eye tracking basically revolves around the concept of recording eye positions and movements. Where the eye is looking, what the eye is looking for, all can be measured with the activity of eye tracking. The process becomes slight complicated when made to come in action as the center of the eye is tracked with respect to the cornea reflection positions. Also known as gaze interaction, eye tracking makes it easy to control the gadgets also. Eye tracking not only tracks the eye movements but also puts the human in control of the device. A device is used for these tracking methods, which is referred to as an eye tracker. These trackers were used to be huge at once, but with the minimizing of the size, also came the advancements in the functioning.

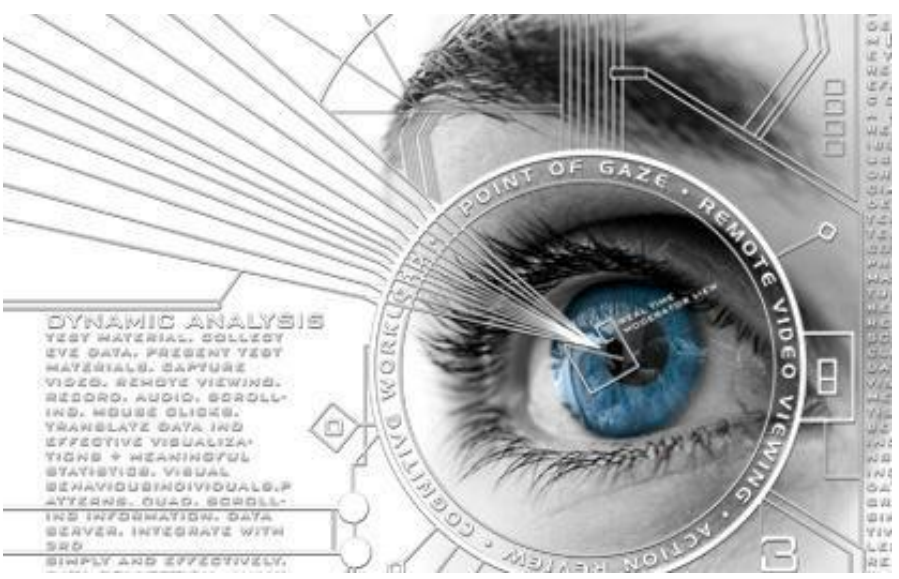

Eye trackers measures interest, arousal and comes as a great device for any kind of human behavior analyses. Using this technology, one can also measure the time for which the eye is gazing at a particular spot. The concept today is becoming more popular, as the evolutions are seen in the technical world. A number of types of eye trackers are available in the market. With the same working principles, these trackers are used for different domains of researches. Medical and psychological researches, market and academic researches, and gaming are some of the widely used fields of application of eye trackers.

Eye tracking is coming as a great way to recognize and analyze, to which sights the person is giving more visual attentions. That's what makes us understand the usefulness of eye tracking in the research purposes. But believe me, it takes many years to bring such kind of inventions in the market. And more years for the adoption of these ideas. And this is the reason that one can think of another 10 years, or fewer, for a technology, like eye tracking, to come in practice for everyday users.

\section{ORIGINATION OF THE TECHNOLOGY}

Today, eye tracking can be seen being applied to a number of research and marketing fields also. But does anyone know what the history behind this magnificent evolution was? For this, we have to go all way back to 1800s.

The very first praxis of eye tracking was seen in the reading works. LOUIS EMILE JAVAL was the one who observed the uneven readings across a page. People used to stop at some particulars and moved quickly through others. Some spots were analyzed to be the favorites of the readers while some were not even looked rightly. A psychologist named EDMUND BURKE HUEY came up with a device, which were actually lenses with a pointer attached. Focus was on to enlighten the highlights on which a reader stopped frequently. Later on, Charles H. Judd and Guy Thomas Buswell started analyzing eye movements and recording them on films with their own device, an EYE MOVEMENT CAMERA. In 1990s, eye tracking technology was used in football professional's game determiners and in late 1990s, world's 


\section{International Journal of Engineering Applied Sciences and Technology, 2019 \\ Vol. 4, Issue 7, ISSN No. 2455-2143, Pages 252-254 \\ Published Online November 2019 in IJEAST (http://www.ijeast.com)}

biggest organizations including marketing agencies started using eye trackers. In 2006, gaming fields also began to come with eye tracking applications. History is long, but eventually a striking technology is there.

\section{AREAS OF APPLICATIONS}

With uniqueness in the concept, eye tracking is today leaving a mark in the society. A number of areas can be seen where eye tracking is there in practice. These areas include applied sciences, research, psychology, marketing, industrial engineering and many more. It will be quite easy to say that eye tracking is not a word applicable only with science or gadgets, but with more common terms like marketing and advertising also. Let us be more familiar.

- The very first use of eye tracking was seen in analyzing human interactions with the gadgets. Eye trackers made it possible to understand the human mind by recording the eye movements and also enhanced the readability of human visions. It captures human's imagination.

- Gaming and virtual reality are the other fields where one can definitely see the applied eye tracking technologies. It was 2006, when for the first time eye tracking came into vision. Gaming with eye tracking gives a different virtual reality to the user. An eye tracker makes it more fun for the gamers. Gaze recording makes it easier to visualize where the gamer is focusing. It feels like we are there in the game itself. Being cheaper and easy to set $\mathrm{u} p$, eye tracking is leaving a great impact in the gaming industry.

- Not only this, but eye tracking can play a good role in market research also. Marketers and entrepreneurs observe their customer's need and areas of interest in their products and markets. They analyze customer behavior so that it could further be used to give a better experience to them.

- The medical science depends on technology at a big rate. Eye imaging is utilized in medical practices. Medical diagnosis, psychological therapies and many more practices are there where eye tracking is applied. Today surgeries can be analyzed and tracked. W here there are automatic surgeries going on, it can be an amazing deal to track those using trackers.

- Package researches also gets better when eye trackers are used for observing that on which packages, the customers are paying more focus through their vision.

\section{FUNCTIONING OF AN EYE TRACKER}

Applications seem to be easy when one knows how to perform them. And for this, a brief description of the tracker's working is required. Let's discuss how an e ye tracker functions and what are the notions behind this glorious and convenient technology.

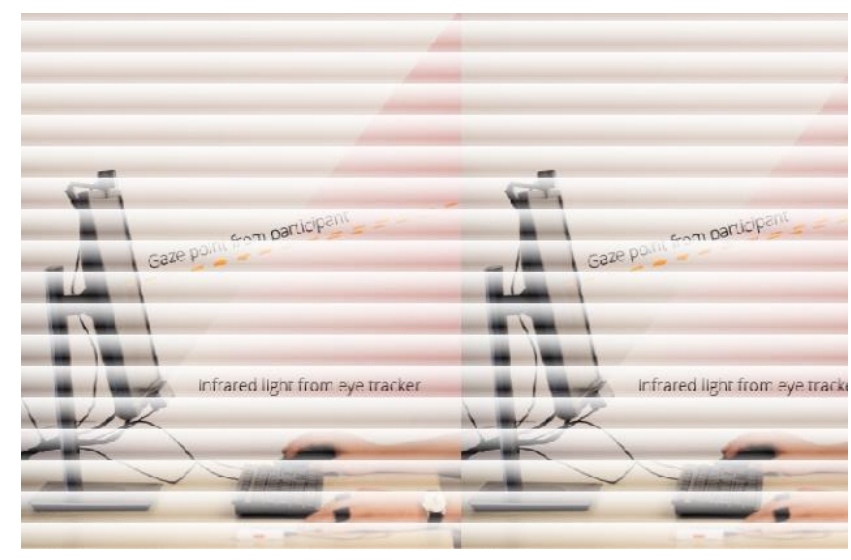

Many types of trackers are $\mathrm{t}$ here in market. Either it can be screen base d monitor or it can be a head-mounted. Ye tracking glasses are also available in market Once we get familiar to the functioning of a technology, it becomes more interesting to use it. Two common components are found in all trackers, light source and a camera. On the very first, light source is directed towards the eye and then the camera comes in action. It records the reflection of light source along with the pupil and this help in tracking the eye movement. Blink tendency and its frequency are also analyzed. Metrics are there which give better quantification that why tracker is to be used. These metrics include:-

\section{- $\quad$ Area of interest Fixations}

- Heat maps

\section{- Fixation sequences Gaze points}

Some remarkable eye trackers can be found today in market. Hardware companies which offer eye tracking gadgets encompasses Tobii, SMI, LC Technologies, ISCAN, EyeTech, The Eye Tribe, an d more.

\section{DAY TO DAY EXAMPLES OF EYE TRACKING}

With a good market acceptance, eye tracking can be practiced in our day to day experiences also. One common usage is detected while using web applications. Trackers definitely seem to be propitious while figuring out mostly viewed advertisings. Website holders record viewer's keen interest in their sites where on the other side, advertisers 


\section{International Journal of Engineering Applied Sciences and Technology, 2019 \\ Vol. 4, Issue 7, ISSN No. 2455-2143, Pages 252-254 \\ Published Online November 2019 in IJEAST (http://www.ijeast.com)}

watch out which advertisements are gaining customer's tempt.

It has been estimated that eye trackers proved to be useful in observing walking of elderly and young people. Young ones use to walk with a high speed. They make use of both central and peripheral vision. This was different in case of elderly people. They depend more on foveal vision, and walk a little slower than young ones.

Eye trackers can be of great use when it comes to analyze navigations. With few mouse clicks and movements, it becomes easy to handle navigations. Navigating routes and real time traffic conditions, all these can be achieved with eye tracking technology.

\section{CONCLUSION}

Eye tracking plays a good role when it comes to track human mind and gaze interactions. A number of hardware companies are there which are offering fascinating eye tracking devices. With some pros and cons, which every technology have, eye tracking is making a good place in research and commercial fields. All that needs to be done is to strengthen the knowledge of eye tracking among different generation. Once, people use to get habitual to this new technology, it will definitely prove to be a revolution in the high tech world of evolutions. It will lead to make a new step for a developing nation and for the coming eras too.

\section{REFERENCES}

[1] Hong Fu, Yeing Wei, Hong Sheng, "Advances in eye tracking technology: theory algorithm and applications", 2016.

[2] Ben Dickson, "Potential of Eye Tracking", pp. 1019$1027,2017$.

[3] IEEE, "A study of eye tracking technology and its applications",2017.

[4] Jon West, " Evaluating the benefits of eye tracking equipments",Article-no-848,2012.

[5] Tad T. Brunye, Trafton Drew" A review of eye tracking for understanding and improving diagnostic interpretation", Article number: 7 (2019).

[6] Gisane Novaes Balam, Ana Alexandra Caldas Osório1, Use Of Eye Tracking, Teoria e Prática, 20(1), 179-188. São Paulo, SP, jan.-abr. 2018.

[7] Shoji Itakura, Eye tracking in an everyday environment reveals the interpersonal distance that affords infantparent gaze communication, Article number: 10352 (2019).

[8] Matteo Cognalato, head mounted eye gaze tracking devices, volume-5, June 11, 2018 .
[9] James Breeze, "Eye Tracking- best way to test rich app usability”, Article No :505 | December 8, 2011.

[10] Z. H. Shokishalov, H. Wang "Applying Eye Tracking In Information Technology", volume-150, 2019, Pages 347351

[11] Andrew T. Duchowski, "A breadth first survey of eye tracking application", November 2002, Volume 34, Issue-4, pp 455-470.

[12] Kharb, L. (2018, January). A Perspective View on Commercialization of Cognitive Computing. In 2018 8th International Conference on Cloud Computing, Data Science \& Engineering (Confluence) (pp. 829-832). IEEE.

[13] J. Dolezal, V. Fabian , "Application of Eye Tracking”, Volume 126, Issue 3, March 2015, Page e44. 